\title{
Saliva as a sampling source for the detection of leukemic fusion transcripts
}

\author{
Dongmei Chen ${ }^{1,2+}$, Najie Song ${ }^{1,2+}$, Runfang $\mathrm{Ni}^{1,2}$, Jiangning Zhao ${ }^{3}$, Jiasheng $\mathrm{Hu}^{3}$, Quanyi $\mathrm{Lu}^{3^{*}}$ and Qingge $\mathrm{Li}^{1,2^{*}}$
}

\begin{abstract}
Background: Saliva has long been used as a sampling source for clinical diagnosis of oral disease such as oral squamous cell carcinoma, or therapeutic drug monitoring. The aims of this study was to ascertain if saliva RNA could be stored at room temperature and to study if saliva could be a convenient source for fusion transcripts in leukemic patients.

Methods: This is a cross-sectional diagnostic study. We first developed a Saliva RNA tube for stable storage of whole saliva RNA at room temperature. Then we detected the leukemic fusions in the whole saliva from seven leukemic patients and twenty healthy volunteers, and compared with the results obtained from the bone marrow of the patients.

Results: Human gene transcripts could be reproducibly detected in the whole saliva for at least four weeks when stored in the developed composition at room temperature. Concordant results of the fusion transcripts were obtained between the saliva and the bone marrow in the seven leukemic patients and no fusions were detected in the healthy controls.
\end{abstract}

Conclusions: The results support our hypothesis that human whole saliva could be a reliable and convenient sampling source for the detection of leukemic fusions.

Keywords: Leukemia, Leukemic fusion transcript, Saliva, Molecular diagnosis, Minimal residual disease

\section{Background}

Leukemic fusion genes generated by chromosome rearrangement are hallmarks of leukemia [1,2]. For examples, the chromosomal abnormalities, $t(9 ; 22)(\mathrm{q} 34 ; \mathrm{q} 11)$ (BCR-ABL), $\mathrm{t}(15 ; 17)(\mathrm{q} 22 ; \mathrm{q} 12)$ (PML-RAR $\alpha)$ and $\mathrm{t}(8 ; 21)$ (q22;q22) (AML-ETO), are present in $90 \%$ to $95 \%$ of chronic myeloid leukemia (CML) cases, in more than 99\% of acute promyelocytic leukemia (APL) cases and in $8 \%$ to $20 \%$ of acute myeloid leukemia (AML) cases, respectively. Detection of fusion transcripts is important in determining the disease status, prognosis, and tailored therapy $[3,4]$. Leukemic fusion transcripts are routinely detected by using whole blood or bone marrow as the

\footnotetext{
* Correspondence: quanyilu@hotmail.com; qgli@xmu.edu.cn

${ }^{\dagger}$ Equal contributors

${ }^{3}$ Zhongshan Hospital of Xiamen, Xiamen University, Xiamen, Fujian 361004, China

'State Key Laboratory of Cellular Stress Biology, State Key Laboratory of Molecular Vaccinology and Molecular Diagnostics, Engineering Research Centre of Molecular Diagnostics, Ministry of Education, School of Life Sciences, Xiamen University, Xiamen, Fujian 361102, China

Full list of author information is available at the end of the article
}

sampling sources. However, either whole blood or bone marrow is difficult to collect, store and transport, and it is often the case that highly trained personnel and expensive facility are required for sampling it. Moreover, the invasive nature of the sampling procedure renders repeated sampling a challenging task, especially, in the case of close monitoring of disease status.

Saliva has long been used as a sampling source for clinical diagnosis [5-13]. Saliva offers advantages over blood and bone marrow for its non-invasive nature, easy storage and transportation, cost-effectiveness, and safe handling [7]. Previous studies showed that $74 \%$ of the total DNA in saliva comes from human leucocytes of various types $[14,15]$. We thus envisioned that the leucocytes in saliva might be a convenient source for the fusion transcripts in leukemic patients. In this cross-sectional diagnostic study, we aims to ascertain if saliva RNA could be stored stably at room temperature and to study if saliva could be a reliable source for the detection of fusion transcripts in leukemic patients. 


\section{Material and methods Subjects}

We recruited 20 healthy individuals from our laboratory and 7 leukemic patients from Zhongshan Hospital of Xiamen for saliva collection in this study between September 2013 and April 2014. The study protocol for sample collection was approved by Research Ethics Committee of Xiamen University and an informed consent was signed for each patient. All subjects were confirmed by licensed dentists to have no mucosal lesion or inflammation in the oral cavity. The oral mucosa appeared healthy, without erythema and epithelial desquamations. The patients were pathologically diagnosed by certified pathologists as CML $(n=2)$, APL $(n=4)$ and AML $(n=1)$, respectively. These patients were examined for BCR-ABL, PML-RAR $\alpha$ or AML-ETO transcripts using bone marrow samples in the hospital. Also, the BCR-ABL was typed into p190 and p210, and PML-RAR $\alpha$ was typed into S, L and V using the same samples. All these molecular assays using bone marrow samples were performed routinely in the hospital through a commercial service. Thirteen of the 27 samples were male and 14 were female. The median age of the subjects was 25 years old (range from 21 to 51 years old). Both of the patients and healthy individuals were the Han nationality.

\section{Sample collection}

To collect human whole saliva for easy transportation, we developed a Saliva RNA tube for stable storage of salivary RNA at room temperature based on a commercial kit [16]. The formed Saliva RNA tube contained $2 \mathrm{~mL}$ of formulated reagent (stabilizer) for RNA stabilization. The stabilizer comprises $4 \%$ sodium dodecyl sulfate (SDS) and $50 \mathrm{mM}$ sodium citrate at $\mathrm{pH}$ 6.8. The principle of this method is that SDS, an anionic detergent, is used to inhibit ribonuclease activity in a weakly acid buffer. Before saliva collection, all subjects were asked to rinse their mouths with water and $2 \mathrm{~mL}$ of whole saliva were collected into the Saliva RNA tube after 30 minutes. Then, the saliva was mixed with the stabilizing liquid from the cap by inversing the tube upside down three times.

\section{RNA extraction and reverse transcription}

From the Saliva RNA tube, $500 \mu \mathrm{L}$ of saliva solution was transferred to a $1.5-\mathrm{mL}$ micro-centrifuge tube, to which $8 \mu \mathrm{L}$ of proteinase $\mathrm{K}$ was added. After a thorough mixing step by inversion, the mixture was incubated overnight at $50^{\circ} \mathrm{C}$ in a water bath followed by heating at $90^{\circ} \mathrm{C}$ for $15 \mathrm{~min}$, then cooled down to room temperature. To the above mixture, $21 \mu \mathrm{L}$ of $\mathrm{KCl}(2.5 \mathrm{M})$ was added and mixed thoroughly by inversion. The mixture was kept on ice for $10 \mathrm{~min}$ and centrifuged $(13,000 \times \mathrm{g})$ at $4^{\circ} \mathrm{C}$ for $10 \mathrm{~min}$. The supernatant was carefully transferred to a fresh micro-centrifuge tube, to which two volumes of cold $95 \%$ ethanol was added and mixed thoroughly by inversion. After storage at $-20^{\circ} \mathrm{C}$ for $1 \mathrm{~h}$, the mixture was centrifuged $(13,000 \times \mathrm{g})$ at $4^{\circ} \mathrm{C}$ for $15 \mathrm{~min}$. The pellet was dissolved into $350 \mu \mathrm{L}$ of buffer RL (RNAprep Pure Micro Kit, Tiangen, Beijing, China), to which $350 \mu \mathrm{L}$ of cold $70 \%$ ethanol was added and mixed. RNA purification was performed immediately using Tiangen RNAprep PureMicro kit. Reverse transcription was carried out using the PrimeScript $^{\oplus}$ RT reagent Kit (TaKaRa, Dalian, China).

\section{Quantitative real-time reverse-transcription (qRT)-PCR}

The transcripts of a commonly used reference gene $\beta$ actin were detected using a qRT-PCR assay. The $25-\mu \mathrm{L}$ reaction consisted of $67 \mathrm{mM}$ Tris- $\mathrm{HCl}(\mathrm{pH} 7.8), 6.7 \mu \mathrm{M}$ EDTA, $16.6 \mathrm{mM}\left(\mathrm{NH}_{4}\right)_{2} \mathrm{SO}_{4}, 0.085 \mathrm{mg} / \mathrm{mL}$ bovine serum albumin, $2 \mathrm{mM} \mathrm{MgCl} 2,25 \mu \mathrm{M}$ of each dNTP, $400 \mathrm{nM}$ of each primer, $100 \mathrm{nM}$ of each probe, $1 \mathrm{U}$ of Taq DNA polymerase and $5 \mu \mathrm{L}$ of cDNA template. qRT-PCR was carried out on the Stratagene Mx3005P Real-Time PCR System (Agilent Technologies, Santa Clara, CA) under the following thermocycling conditions: $95^{\circ} \mathrm{C}$ for $10 \mathrm{~min}$, followed by 50 cycles of $95^{\circ} \mathrm{C}$ for $15 \mathrm{~s}, 58^{\circ} \mathrm{C}$ for $20 \mathrm{~s}$, and $72^{\circ} \mathrm{C}$ for $30 \mathrm{~s}$. Each sample was performed in duplicate (sic passim). Leukemic fusion transcripts were detected using Q-Fusion (QuanDx, San Francisco, CA), a multiplex qRT-PCR assay that detects 30 common leukemic fusions. BCR-ABL fusion was then typed using a BCR-ABL typing (p190, p210) assay, and PML-RAR $\alpha$ was typed using a PML-RAR $\alpha$ typing ( $\mathrm{L}, \mathrm{V}, \mathrm{S})$ assay (QuanDx), respectively. qRT-PCR was performed in the Stratagene Mx3005P Real-Time PCR System following the manufacturer's protocol.

\section{Results}

Stability of RNA extracted from the whole saliva stored at room temperature

We first tested whether human gene transcripts in the whole saliva could be reproducibly detected after storage at room temperature. For this purpose, saliva samples were collected from two healthy individuals, one male and one female. RNA was extracted and subjected to qRT-PCR for $\beta$-actin mRNA analysis at intervals between 0 to 4 weeks. Our results showed that the quantification cycle $(\mathrm{Cq})$ values of $\beta$-actin mRNA kept nearly constant for 4 weeks (Figure 1A), demonstrating that the mRNA level of $\beta$-actin in the saliva remained largely unchanged during the 4-week storage at room temperature. The differences of $\mathrm{Cq}(\Delta \mathrm{Cq})$ between the $\mathrm{RT}(+)$ and $\mathrm{RT}(-)$ were larger than 10 (Figure $1 \mathrm{~B}$ ), indicating that there was negligible $(<0.1 \%)$ contamination of human genomic DNA [17]. We thus concluded that human gene transcripts could be detected in the whole saliva and remain stable for at least four weeks when stored in the Saliva RNA tube at room temperature. 

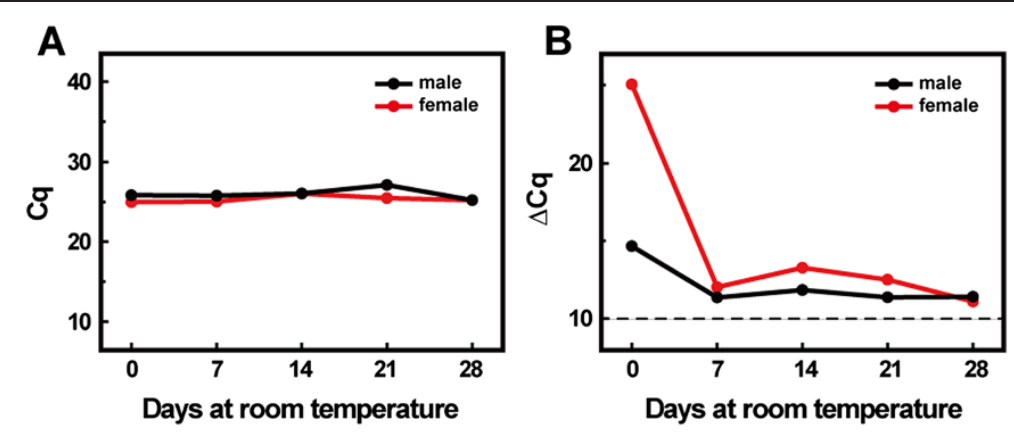

Figure 1 The stability of RNA extracted from the whole saliva stored at room temperature. Saliva was collected respectively from two healthy individuals and stored in the Saliva RNA tubes for up to four weeks. Total RNA was extracted at different time intervals. The transcripts of $\beta$-actin were detected using the qRT-PCR assay at different weeks. (A) The Cq values of the the two samples at different weeks. The Cq for the male and female saliva were calculated to be $26.00 \pm 0.70$ and $25.34 \pm 0.43$, respectively. (B) The $\Delta$ Cq values of the two samples at different weeks. $\Delta \mathrm{Cq}=\mathrm{Cq}_{\mathrm{RT}(-)}-\mathrm{Cq}_{\mathrm{RT}(+)}$, where $\mathrm{Cq}_{\mathrm{RT}(+)}$ was the $\mathrm{Cq}$ values obtained from the extracted RNA with reverse transcription, whereas $\mathrm{Cq}_{\mathrm{RT}(-)}$ was the $\mathrm{Cq}$ values obtained without reverse transcription.

Detection of fusion transcripts in saliva from both healthy individuals and leukemia patients

We then tested whether leukemia-specific fusion gene transcripts could be detected in the whole saliva of the leukemic patients. To this end, whole saliva was collected from each of the 27 recruited individuals including 20 healthy individuals and 7 leukemic patients. The saliva samples obtained were renumbered. After RNA extraction, the samples were subjected to the Q-Fusion assay in a blind format. The results showed that 20 samples were negative for leukemic fusions, 2 positive for BCR-ABL, 4 positive for PML-RAR $\alpha$, and 1 positive for AML-ETO
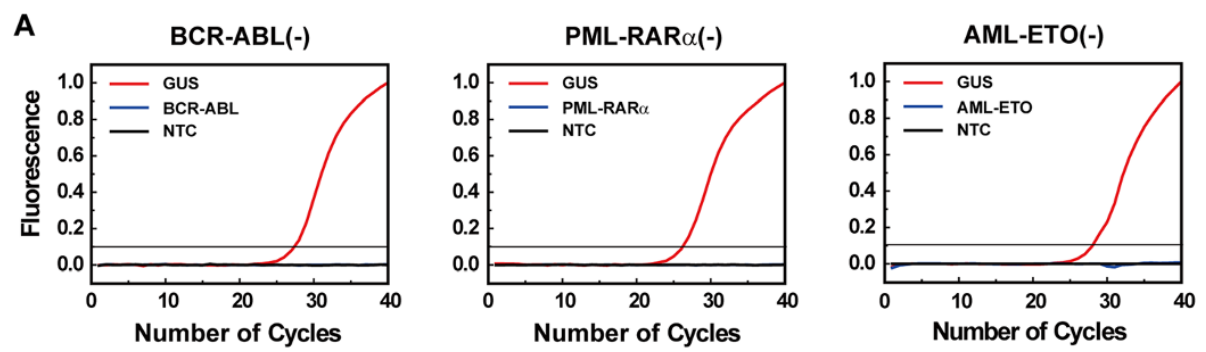

B

CML


Figure 2 Detection of fusion transcripts in saliva from both healthy individuals and leukemic patients. (A) qRT-PCR results of the representative healthy individuals for the detection of BCR-ABL, PML-RARa, and AML-ETO. (B) QRT-PCR results of the three types of leukemia patients for the detection of BCR-ABL, PML-RARa, and AML-ETO. The upper panel showed the pathological results for the patients and the lower panel showed the corresponding qRT-PCR results. In all detections, GUS was used as the reference gene and water was used as the no-template control (NTC). 

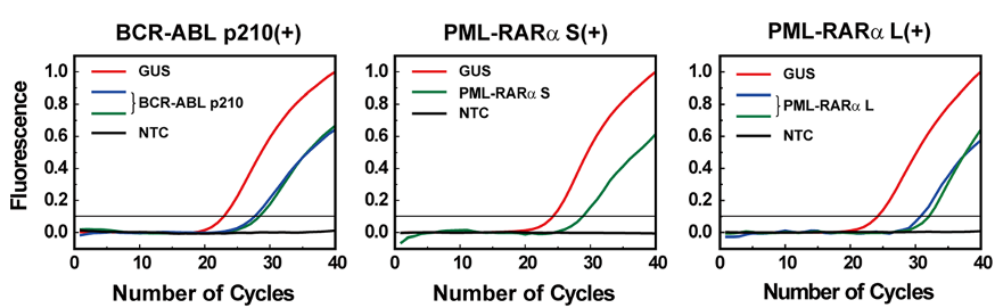

Figure 3 Determination of the type of fusion transcripts in saliva from leukemic patients. qRT-PCR results of the CML and APL patients for the typing of BCR-ABL and PML-RARa, respectively. In all detections, GUS was used as the reference gene and water was used as the no-template control (NTC).

(Figure 2). By referring to the results from the hospital, a complete agreement between the two assays was achieved. The qRT-PCR results also agreed with the pathological diagnosis, i.e., the 2 samples positive for BCR-ABL were from the CML patients, 4 positive for PML-RAR $\alpha$ were from the APL patients, and 1 positive for AML-ETO was from the AML patient (Figure 2). These results demonstrated that leukemic fusion transcripts could be accurately detected in the whole saliva of the leukemic patients.

\section{Determination of the type of fusion transcripts in saliva from leukemic patients}

Using the same saliva samples, we further determined the type of the two BCR-ABL samples from the CML patients and the four PML-RAR $\alpha$ samples from the APL patients. The results showed that both the CML patients had p210 subtype for BCR-ABL, three APL patients had S subtype, and one APL patient had L subtype for PMLRARa (Figure 3). In comparison with the results obtained from the hospital where the typing assays using bone marrow samples were performed routinely through a commercial service, a complete concordance was again achieved. We thus concluded that the type of the fusion transcripts could also be correctly determined in the whole saliva of the leukemic patients. Taken together, we confirmed that leukemic fusion transcripts could be detected in the saliva of the leukemic patients.

\section{Discussion}

This is the first report of using saliva as a sampling source for the detection of leukemic fusion transcripts. It has long been regarded that salivary RNA is from oral epithelial cells and oral micro-organisms [18]. Therefore salivary RNA has been already used for diagnosis of oral carcinoma and oral infection. Recent studies on the use of salivary transcriptomic biomarkers for detection of pancreatic cancer [19] and breast cancer [12] suggest that salivary RNA might also be used to detect those conditions other than oral diseases.

In this preliminary study, we demonstrated that leukemic transcripts could be reliably detected from salivary RNA and the detection results from saliva fully agreed with those obtained from bone marrow. The small sampling of this study precludes us to calculate the sensitivity or specificity values of the testing, however, the facts that human RNA in saliva could be stably stored and repeatedly detected support the diagnostic value of our study.

Saliva collection is a truly non-invasive sampling format, and repeated sampling can be easily performed. Because no risk of infection exists and no expertise is needed, sampling can be carried out at home by the patient, stored at room temperature, and sent to the hospital through surface mail. Not only the cost is substantially reduced, the way of disease management can also be significantly improved.

The success of the detection of fusion transcripts using saliva as sampling source by qRT-PCR might also be extended to other diagnostic approaches for leukemia diagnosis such as cytogenetic analysis and fluorescence in situ hybridization. Further studies are now being undertaken to clarify the association of fusion transcript level among saliva, blood, and bone marrow in a quantitative format. Such an association might allow the potential use of saliva for the detection of the minimal residual disease in leukemia.

\section{Conclusions}

This study developed a composition for stable storage of saliva RNA at room temperature and confirmed that saliva can be used as a sampling source for the detection of leukemic fusion transcripts. Saliva offers advantages over blood and bone marrow for its non-invasive nature, easy storage and transportation, cost-effectiveness, and safe handling. We thus expect that the adoption of saliva sampling would advance the development of new paradigms for diagnosis, prognosis, and tailed therapy of leukemia.

Competing interests

The authors declare that they have no competing interests.

Authors' contributions

LQG, CDM and SNJ designed the research and contributed vital new reagents. CDM and NRF conducted experiments. LQG, CDM and SNJ performed data analysis. ZJN and HJS collected samples and performed the histopathological analyses. LQG, CDM and LQY wrote or contributed to the 
writing of the manuscript. All authors read and approved the final manuscript.

\section{Acknowledgements}

The study protocol for sample collection was approved by Research Ethics Committee of Xiamen University and an informed consent was signed for each patient. The study was partially supported by National Natural Science Foundation No. 81172246 and National Basic Research Program of China Grant No. 2010CB732402.

\section{Author details}

${ }^{1}$ State Key Laboratory of Cellular Stress Biology, State Key Laboratory of Molecular Vaccinology and Molecular Diagnostics, Engineering Research Centre of Molecular Diagnostics, Ministry of Education, School of Life Sciences, Xiamen University, Xiamen, Fujian 361102, China. ${ }^{2}$ Shenzhen Research Institute of Xiamen University, Shenzhen, Guangdong 518057, China. ${ }^{3}$ Zhongshan Hospital of Xiamen, Xiamen University, Xiamen, Fujian 361004, China.

Received: 9 August 2014 Accepted: 5 November 2014

Published online: 19 November 2014

\section{References}

1. Chaganti R: Significance of chromosome change to hematopoietic neoplasms. Blood 1983, 62:515-524.

2. Rowley JD: The critical role of chromosome translocations in human leukemias. Annu Rev Genet 1998, 32:495-519.

3. Mitelman F, Johansson B, Mertens F: The impact of translocations and gene fusions on cancer causation. Nat Rev Cancer 2007, 7:233-245.

4. Fröhling S, Döhner $\mathrm{H}$ : Chromosomal abnormalities in cancer. New Engl J Med 2008, 359:722-734.

5. Horning MG, Brown L, Nowlin J, Lertratanangkoon K, Kellaway P, Zion TE: Use of saliva in therapeutic drug monitoring. Clin Chem 1977, 23:157-164.

6. Workman P, Wiltshire C, Plowman P, Bleehen NM: Monitoring salivary misonidazole in man: a possible alternative to plasma monitoring. Brit Cancer 1978, 38:709.

7. Malamud D: Saliva as a diagnostic fluid. Brit Med J 1992, 305:207.

8. Streckfus C, Bigler L, Dellinger T, Dai X, Kingman A, Thigpen JT: The presence of soluble c-erbB-2 in saliva and serum among women with breast carcinoma: a preliminary study. Clin Cancer Res 2000, 6:2363-2370.

9. Hofman LF: Human saliva as a diagnostic specimen. J Nutr 2001, 131:1621S-1625S.

10. Mager D, Haffajee A, Devlin P, Norris C, Posner M, Goodson J: The salivary microbiota as a diagnostic indicator of oral cancer: a descriptive, non-randomized study of cancer-free and oral squamous cell carcinoma subjects. J Trans/ Med 2005, 3:27.

11. Pfaffe T, Cooper-White J, Beyerlein P, Kostner K, Punyadeera C: Diagnostic potential of saliva: current state and future applications. Clin Chem 2011, 57:675-687.

12. Lau CS, Wong DT: Breast cancer exosome-like microvesicles and salivary gland cells interplay alters salivary gland cell-derived exosome-like microvesicles in vitro. PLoS One 2012, 7:e33037.

13. Ciregia F, Giusti L, Da Valle Y, Donadio E, Consensi A, Giacomelli C, Sernissi F, Scarpellini P, Maggi F, Lucacchini A: A multidisciplinary approach to study a couple of monozygotic twins discordant for the chronic fatigue syndrome: a focus on potential salivary biomarkers. J Transl Med 2013, 11:243.

14. Rindom Schiött C, Löe H: The origin and variation in number of leukocytes in the human saliva. J Periodontal Res 1970, 5:36-41.

15. Thiede C, Prange-Krex G, Freiberg-Richter J, Bornhäuser M, Ehninger G: Buccal swabs but not mouthwash samples can be used to obtain pretransplant DNA fingerprints from recipients of allogeneic bone marrow transplants. Bone Marrow Transp/ 2000, 25:575

16. Birnboim HC, Jackson A: Stabilizing compositions and methods for extraction of ribonucleic acid. WO patent 2008, 2008040126:A1.
17. Erickson HS, Albert PS, Gillespie JW, Rodriguez-Canales J, Linehan WM, Pinto PA, Chuaqui RF, Emmert-Buck MR: Quantitative RT-PCR gene expression analysis of laser microdissected tissue samples. Nat Protoc 2009, 4:902-922.

18. Fábryová $\mathrm{H}$, Celec P: On the origin and diagnostic use of salivary RNA. Oral Dis 2014, 20:146-152.

19. Zhang L, Farrell JJ, Zhou H, Elashoff D, Akin D, Park NH, Chia D, Wong DT: Salivary transcriptomic biomarkers for detection of resectable pancreatic cancer. Gastroenterology 2010, 138:949-957.

doi:10.1186/s12967-014-0321-z

Cite this article as: Chen et al:: Saliva as a sampling source for the detection of leukemic fusion transcripts. Journal of Translational Medicine 2014 12:321.

\section{Submit your next manuscript to BioMed Central and take full advantage of:}

- Convenient online submission

- Thorough peer review

- No space constraints or color figure charges

- Immediate publication on acceptance

- Inclusion in PubMed, CAS, Scopus and Google Scholar

- Research which is freely available for redistribution 